\title{
REFRACTIVE RESULTS AFTER CORNEAL TRIPLE PROCEDURES (PK+ECCE+IOL)
}

\author{
CHARLES CLAOUÉ, LINDA FICKER, COLIN KIRKNESS and ARTHUR STEELE \\ London
}

\begin{abstract}
SUMMARY
We have analysed the refractive results of corneal triple procedures (penetrating keratoplasty with extracapsular cataract extraction and posterior chamber intraocular lens implantation) in 52 eyes of 47 patients with a mean follow-up of 39 months. The patients were predominantly old and female and most received unilateral surgery. The contralateral acuity was $6 / 24$ or worse in more than $50 \%$ of cases at the time of surgery. Many of these patients were significantly ametropic pre-operatively. Biometry does not seem to have improved the refractive results in those patients in whom it was attempted. The majority of patients were hypermetropic when their refraction stabilised, with resulting poor uncorrected visual performance. Possible improvements are discussed.
\end{abstract}

Simultaneous cataract and corneal surgery is indicated in those patients in whom coexisting disease reduces vision to unacceptable levels. ${ }^{1,2}$ It may also be indicated for those patients in whom cataract surgery is likely to result in corneal decompensation, or in whom corneal surgery is likely to accelerate cataractogenesis. ${ }^{3}$ In general, simultaneous surgery is preferred as the patient is only subjected to a single anaesthetic, although a recent review of sequential cataract surgery after penetrating keratoplasty shows that, with modern microsurgical techniques of extracapsular surgery and the use of viscoelastic substances, graft survival is good. ${ }^{4}$

During recent years the corneal triple procedure (penetrating keratoplasty with extracapsular cataract extraction and posterior chamber intraocular lens implantation: $\mathrm{PK}+\mathrm{ECCE}+\mathrm{IOL}$ ) has become the treatment of choice at Moorfields Hospital for these patients. At some hospitals, a single surgeon will perform all the procedures, whereas at many others the surgery will be performed by a number of ophthalmologists. We wished to ascertain the epidemiological parameters and refractive results of patients undergoing corneal triple procedures at Moorfields, where surgeons including those in training are involved in the care of such patients.

Correspondence to: Mr. C. Claoué, The Corneal Clinic, Moorfields Eye Hospital, City Road, London EC1V 2PD, UK.

\section{MATERIALS AND METHODS}

In December 1990 the diagnostic index of the Moorfields Corneal Clinic was searched for patients who had undergone corneal triple procedures and who had been reviewed in the Clinic since the instigation of the diagnostic index in 1985.

The hospital records were examined and data extracted to a spread-sheet. Data sought were (1) patient identifiers, (2) epidemiological data including age, sex and distance from home address to Moorfields, and (3) cause of corneal opacity, refractive outcome, complications and rejection episodes, and whether further surgery was required. Where the data was available, pre-morbid refractions were noted. Pre-operative acuity of both eyes and details of biometry (if any) were noted, as was suture technique and other operative details. Post-operatively, the numbers of clinic visits during the first year's trimesters and second year's semesters were recorded. 'Final' refraction was defined as a stable refraction (less than 0.5 dioptre change) for two successive clinic visits, or the latest refraction if follow-up exceeded 2 years. This data-base included the parameters shown in Table I. The data were then analysed.

\section{RESULTS}

Fifty-one patients were identified who had undergone cor-

Table 1. Parameters studied for patients receiving corneal triple procedures

\section{Patient identifier}

Distance to home address

Diagnosis

Age at surgery

Pre-operative acuities and refraction

Biometry

Grade of surgeon

Graft storage technique

Suture technique

Post-operative acuity and refraction

Clinic visits in 3-monthly periods for the first year

Clinic visits in 6-monthly periods for the second year

Graft refractive surgery and results

Glaucoma; other ophthalmic pathology 
Table II. Diagnoses in 52 eyes requiring corneal triple procedures (all patients also had cataract)

\begin{tabular}{lc}
\hline Diagnosis & No. of patients \\
\hline Fuchs' endothelial dystrophy & 24 \\
Interstitial keratitis & 7 \\
Failed corneal graft & 5 \\
'Scar' & 4 \\
Stromal dystrophies & 3 \\
Keratoconus & 3 \\
Miscellaneous & 6 \\
\hline
\end{tabular}

neal triple procedures. Forty-seven sets of hospital notes were available $(92 \%)$.

\section{Epidemiological Data}

The 31 female and 16 male patients had a mean age at the time of surgery of 69.5 years. Five patients had bilateral corneal triple procedures; 4 were female. There was no significant difference between the numbers of right or left eyes receiving surgery, nor the ages of male or female patients, nor of the ages of patients receiving unilateral or bilateral surgery.

The mean distance from home to Moorfields was 29.3 miles \pm 36.0 , with $34 \%$ of patients travelling more than 30 miles to the hospital. However, those patients who received bilateral surgery lived a mean of $16.6 \pm 10.5$ miles from the hospital.

\section{Surgical and Refractive Data}

The commonest diagnosis was Fuchs' endothelial dystrophy; other diagnoses are shown in Table II. More than half the patients had 6/24 vision or more in their fellow eye, whilst more than a quarter had CF (counting fingers) vision or worse, as shown in Table III.

For 21 of the 51 eyes (40\%), pre-cataractous refractions were available. These showed more than 5 dioptres of ametropia in at least one axis in 4 (19\%) eyes.

Seven of the 42 unilateral procedures $(17 \%)$ were performed by surgeons in training, whereas they performed 4 of the 10 bilateral procedures. Fifty-six per cent of the donor eyes had been banked as corneo-scleral preparations, and the remainder as whole eyes stored in moist chambers. Suturing was with continuous $10 / 0$ in 30 cases, interrupted in 18 and a mixture $(8+8)$ in 4 patients. Most grafts were between 7 and $8 \mathrm{~mm}$ in diameter and in all cases a viscoelastic agent was used. In general the donor was trephined using a trephine $0.5 \mathrm{~mm}$ larger than that used for the host.

Table III. Visual acuity in the fellow eye at the time of corneal triple procedures

\begin{tabular}{lc}
\hline Acuity in fellow eye & $\%$ of patients \\
\hline 6/9 or worse & 100 \\
$6 / 12$ or worse & 92 \\
$6 / 18$ or worse & 78 \\
$6 / 24$ or worse & 56 \\
$6 / 36$ or worse & 46 \\
6/60 or worse & 40 \\
CF or worse & 26 \\
\hline
\end{tabular}

$\mathrm{CF}$, counting fingers.
For 32 patients, an attempt was made to calculate the power of the intraocular lens (IOL) for planned emmetropia. Fifteen patients had a standard +21 dioptre lens inserted without biometry, and in 5 cases a planned alteration was made to the standard IOL power consistent with the refractive history (e.g. myopic in early adulthood).

Mean follow-up per eye was 39.04 months \pm 19.9 . Seventy-four per cent of eyes had a follow-up of 2 years or more, and $88 \%$ of 1 year or more. Only a single eye had less than 6 months' follow-up.

Best corrected visual acuity was improved post-operatively for all patients except 2 , one of whom lost one line of Snellen acuity due to age-related macular changes whilst the other had an evisceration following fulminant Pseudomonas endophthalmitis. Mean improvement in acuity was by five Snellen lines (SD \pm 2 ). There was no significant difference between the acuities of patients receiving grafts from banked corneo-scleral rings or whole eyes, nor between those in whom surgery was performed by consultants or by surgeons in training. Eleven patients had documented causes of poor post-operative vision. These included age-related macular degeneration $(n=3)$, glaucoma $(n=2)$ and optic atrophy $(n=1)$. One patient had a primary graft failure. Two patients developed glaucoma following their corneal triple procedures. Nine eyes (18\%) suffered rejection episodes with a mean of 1.3 episodes per eye; none had more than two episodes. Only one corneal graft decompensated after a rejection episode occurring 19 months after surgery. The probability of graft survival for this group of patients is shown in Fig. 1.

All post-operative refractions were transposed to negative cylinders for analysis. Mean time to first two refractions was $3.6 \pm 3.1$ and $8.0 \pm 5.0$ months. After transposition of the 'final' refractions, $70 \%$ of patients had a hypermetropic correction and $30 \%$ a myopic correction as shown in Fig. 2. The range of spherical ametropia (i.e. the spherical component of the refractive error) was from +10 to -11 spherical dioptres (DS). The mean spherical ametropia (i.e. ignoring whether + or - sphere) was compared between the groups in whom the IOL power was calculated, planned and standardised. The results are shown in Table IV and Fig. 3.

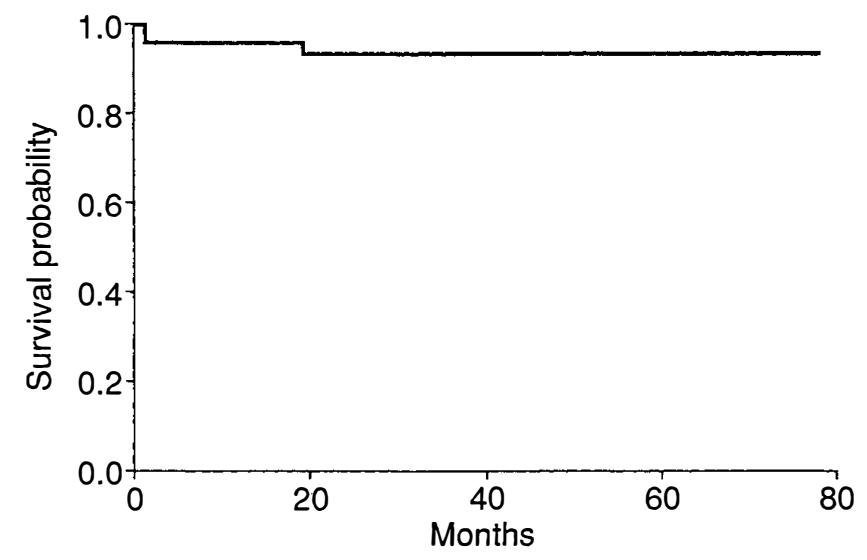

Fig. 1. Graft survival curve for patients receiving corneal triple procedures. Survival probability at 1 month was 0.96 , at 19 months 0.94 , and at 78 months 0.94 . 


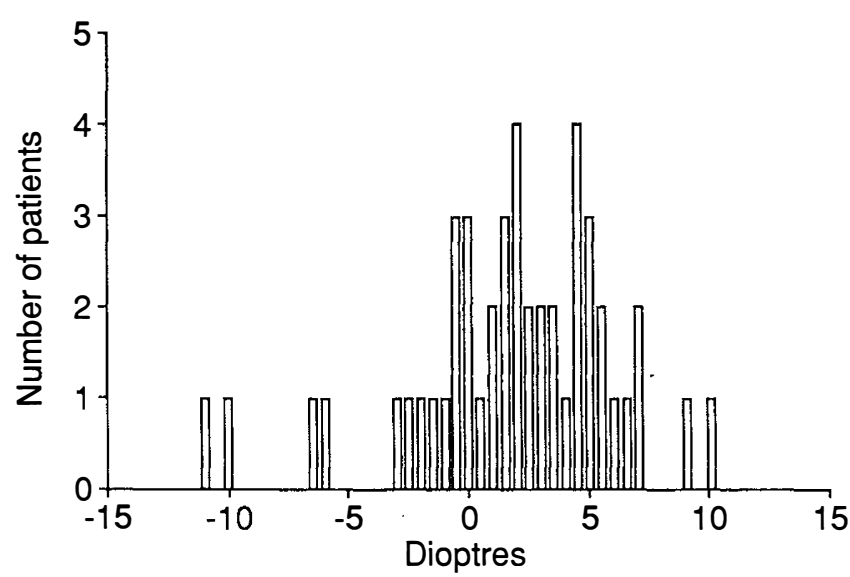

Fig. 2. Spherical component ametropia for patients receiving corneal triple procedures.

One patient had no astigmatism; for the others the mean astigmatic error was 4.33 cylindrical dioptres (DC) \pm 2.9 . The range of astigmatic error was from 0 to $-31 \mathrm{DC}$ as shown in Fig. 4. There was no significant difference in the degree of astigmatism between left $(4.4 \pm 2.2 \mathrm{DC})$ or right $(4.2 \pm 3.5 \mathrm{DC})$ eyes, between those in whom surgery was performed by consultants $(4.2 \pm 2.7 \mathrm{DC})$ or by surgeons in training $(4.6 \pm 3.9 \mathrm{DC})$, nor between those in whom banked $(4.0 \pm 1.9 \mathrm{DC})$ or whole-eye $(3.9 \pm 3.1$ DC) material was used. There was also no significant difference in the final astigmatic error according to whether the patient had continuous suturing of the hostgraft interface $(4.3 \pm 2.3 \mathrm{DC})$ or interrupted sutures $(5.1 \pm 3.9 \mathrm{DC})$. For $26 \%$ of eyes, both refractive meridia were hypermetropic.

Six patients received graft refractive surgery at a mean of 26 months \pm 15.2 after their original corneal triple procedure. One patient refused this procedure and 1 was awaiting surgery, giving an overall graft refractive surgery rate of $15.4 \%$ for the whole group. At the time of assessment, an optical correction had been dispensed for 36 eyes $(69 \%)$ at a mean of 11.5 months after surgery (SD \pm 7.3 months).

The numbers of outpatient visits during the first and second post-operative years are given in Table V. It can be seen that patients averaged a mean of 10.8 clinic visits in their first post-operative year and 5.6 in the second.

\section{DISCUSSION}

\section{Historical Perspective}

Combined simultaneous surgery for cataract and corneal

Table IV. Mean spherical ametropia in spherical equivalents in patients receiving corneal triple procedures, with attempted calculation of IOL power ('calculated'), planned alteration of power in line with refractive history ('planned'), or standard +21 DS IOL ('standard')

\begin{tabular}{lcc}
\hline Group & No. of patients & $\begin{array}{c}\text { Ametropia } \\
(\text { mean } \pm \text { SD) }\end{array}$ \\
\hline Calculated & 31 & $4.28 \pm 3.69$ \\
Planned & 5 & $2.50 \pm 2.73$ \\
Standard & 15 & $2.16 \pm 1.85$ \\
\hline
\end{tabular}

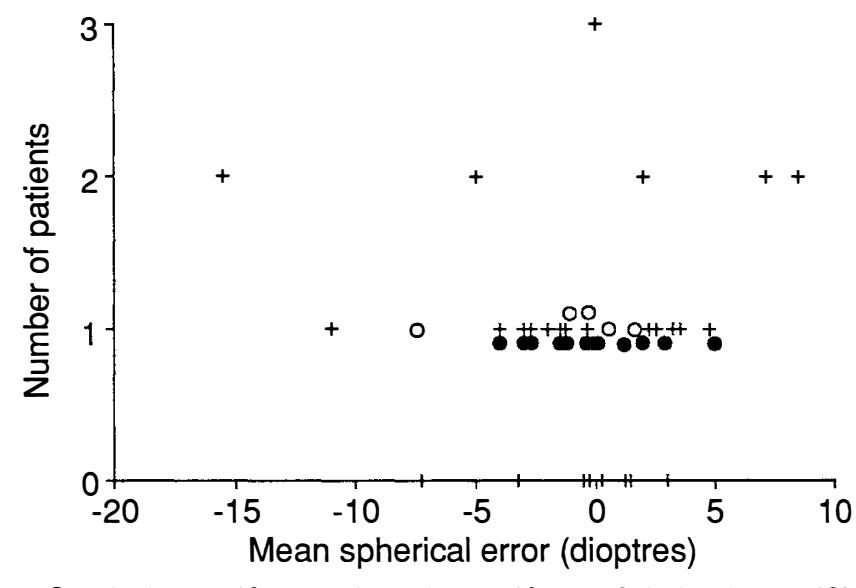

- Standard power IOL O Planned power IOL + Calculated power IOL

Fig. 3. Comparison of mean spherical ametropia following corneal triple procedure using standard, planned or calculated IOL powers (see text for definitions).

disease was first described by Katzin and Meltzer, ${ }^{1}$ and 10 years later the simultaneous use of IOL implantation was introduced by Taylor. ${ }^{2}$ With the advent of modern extracapsular cataract surgery and posterior chamber lenses, this has become a frequently performed operation termed the 'triple procedure'.

\section{Overview of the Problem}

A number of previous publications ${ }^{5-9}$ have supported our initial experience that this surgery is an effective way of restoring good vision in patients with combined corneal disease and cataract. ${ }^{10}$ However, the problem of providing the patient with a predictable refractive error remains. As Geggel ${ }^{11}$ has elegantly stated: 'corneal surgeons now have the luxury to worry about the post-operative refractive error ... and not just whether the graft remains clear'.

The final refractive error depends on the corneal curvature, the power of the IOL and the axial length of the eye. For a simple cataract extraction the major variable is the IOL power, and in this situation the refractive outcome is highly predictable. The variables involved for a triple procedure are much greater. Clearly, penetrating keratoplasty will alter the keratometry readings, although Crawford $e t$ $a l .{ }^{7}$ have shown that they provide some basis for IOL cal-

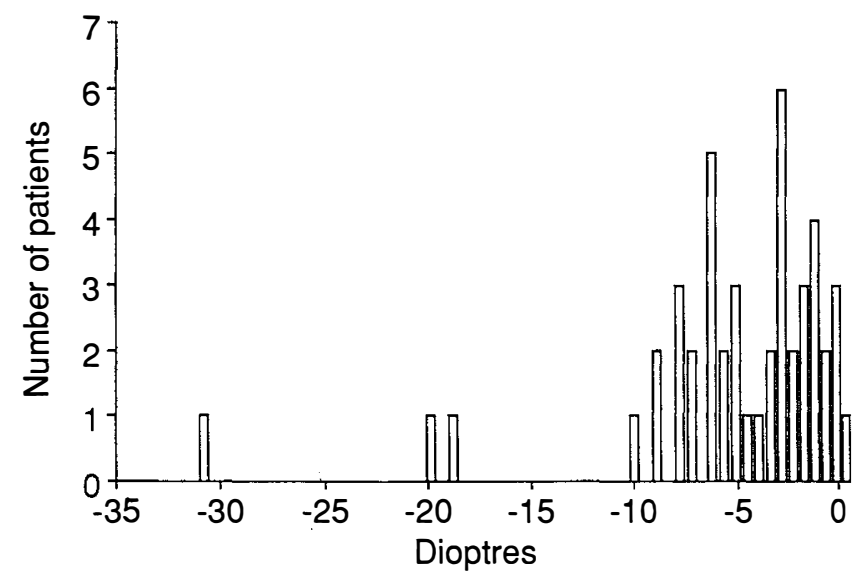

Fig. 4. Astigmatic error following corneal triple procedures. 
Table V. Mean number of outpatient visits (OPVs) during the four quarters of the first post-operative year and the two semesters of the second post-operative year, showing standard deviations from the mean and range of values (in brackets)

\begin{tabular}{ll}
\hline Time post-op. (months) & No. of OPVs \\
\hline $0-3$ & $4.6 \pm 1.8(2-10)$ \\
$4-6$ & $2.5 \pm 1.1(1-6)$ \\
$7-9$ & $2.0 \pm 1.2(0-6)$ \\
$10-12$ & $1.7 \pm 1.5(0-8)$ \\
$13-18$ & $3.0 \pm 2.2(0-9)$ \\
$19-24$ & $2.6 \pm 1.6(0-7)$ \\
\hline
\end{tabular}

culation. Several exponents have suggested that for a single surgeon using a standardised technique the mean keratometry is predictable ${ }^{6,8,9}$ but this precludes teaching surgeons in training and minimises the spread of technical skills. In addition, it presupposes a series of patients from whom the post-operative keratometry can be obtained. Whilst the concept of a personalised A-constant for the calculation of IOL power for corneal triple procedures is attractive, the majority of surgeons do not perform enough procedures on which to base such a calculation. No single formula has been devised which accurately predicts IOL power for several surgeons. ${ }^{7}$ The other main variable invoked for deciding the IOL power is the axial length. Modern biometry machines provide accurate estimates, and although the axial length will alter slightly after a triple procedure this does not seem to be a major determinant of the refraction even in the extreme case of patients with keratoconus. ${ }^{6}$

A further problem is with the presentation of the refractive results. What is the earliest time at which 'final' refraction can be derived? Should all sutures be removed before the 'final' refraction is reported? Furthermore, there is great variability in the method of reporting refractive results. Some authors use the term 'mean refractive error' for their patient population (and it is not clear that they have not allowed high myopic and high hypermetropic errors to cancel each other). Many authors refer to 'mean spherical error' and report a high proportion of their patients within the range of +2 to -2 . However, a refraction of $+4.00 /-6.00 \times 180^{\circ}$ gives a mean spherical error of +1.00 yet it is unlikely that this eye has either good unaided vision or that the correction will be tolerated as a spectacle lens if the fellow eye sees $6 / 5$ with -2.00 / $-0.50 \times 90^{\circ}$. Some authors have limited their results to the mean spherical errors of their patients with good vision, ${ }^{9}$ despite the fact that high or irregular astigmatism might have degraded the vision for other patients in their series. We have therefore preferred to convert all our final refractions to a minus cylinder and then report the proportion with myopic or hypermetropic spherical errors. We have used the term 'mean spherical ametropia' which is independent of whether the lens is positive or negative.

\section{Diagnoses}

The majority of our patients were elderly and female, as has been the experience of others. ${ }^{6,711}$ Although it might seem surprising to find several patients with keratoconus amongst those requiring corneal triple procedures in our series, other series have also included such patients. ${ }^{6,9,11,12}$ Patients with atopy, keratoconus and atopic cataracts and those with Down's syndrome cataract and keratoconus are recognised candidates for corneal triple procedures. ${ }^{6,9,11}$ Although the commonest diagnoses were bilateral conditions, other authors have also reported that only a minority of patients require bilateral surgery. ${ }^{12}$

\section{Geography}

Hitherto, the referral of patients in the National Health Service for care has been relatively unhindered. Despite this, little is known about how far patients travel for specialist surgical care. The catchment area for this procedure and this hospital is approximately 2700 square miles, but the precise population is unknown. There are a number of other hospitals within this area that are capable of such surgery, but the proportion performed at Moorfields is unknown. Interestingly, approximately one third of the patients came from outside greater London. It is not clear why those patients who received bilateral surgery appear to live closer to the hospital (within an area of 365 square miles). It may be that having recovered good vision in one eye, those who had to travel furthest did not feel that the restoration of binocular vision warranted travelling the distance involved.

\section{Vision in the Other Eye}

This study demonstrates that vision in the contralateral eye was frequently also poor at the time of surgery, and is in keeping with the report by Claoue et al. ${ }^{13}$ This aspect of patients requiring penetrating keratoplasty has not previously been investigated in detail, and our study appears to confirm that, in general, such surgery is used to restore vision rather than binocularity. Coster ${ }^{14}$ reported that satisfaction following penetrating keratoplasty is related to superior vision in the grafted eye, and corneal surgeons are clearly at least subconsciously aware of this in selecting their cases.

If the vision in the unoperated fellow eye is poor, then the refraction that will be tolerated post-operatively could be more ametropic and more astigmatic than if the contralateral eye sees well, as patient motivation to adapt to the new refraction is likely to be higher and anisometropia is less likely to be a problem. Recently Geggel ${ }^{11}$ has argued cogently for a two-stage procedure (PK+ECCE followed by IOL after stabilisation of keratometry) to counter the refractive problems frequently encountered after a one-stage procedure. Although his patients do not appear significantly younger than those in other series, he does comment that 'most ... had reasonable vision in their fellow eye' and that therefore his patients did not object to a period of uncorrected aphakia prior to IOL implantation. Although Geggel's series is small, his high proportion $(68 \%)$ with $6 / 12$ uncorrected visual acuity is remarkable and far exceeds other published data. ${ }^{8}$ It may be that for young patients with good contralateral vision a 
two-stage procedure $(\mathrm{PK}+\mathrm{ECCE}$ followed by IOL after stabilisation of keratometry) should be considered, but the significant advantages of a single surgical procedure and in-the-bag placement of the IOL will be lost. An alternative would be PK followed by ECCE+IOL, which would allow in-the-bag placement but subjects the corneal graft to a more extensive secondary surgical procedure which carries some risk of graft failure.

\section{Complications}

The complications in this series are unremarkable and similar to those of others, with the exception of the fulminant Pseudomonas endophthalmitis which destroyed the eye of one patient. Our rejection rate of $18 \%$ and graft refractive surgery rate of $12 \%$ compare well with published data. ${ }^{7,11}$

\section{Refractive Results: Spherical Error}

Although pre-morbid refractions were available for only a minority of patients, and whilst these might have been seriously affected by lenticular index changes, they do suggest that if this sample is typical of the population under study, then our patients have a significant incidence of ametropia. This clearly will contribute to post-operative ametropia unless appropriate measures are taken to reduce it by alterations in the power of the IOL to be implanted. Pitts and Jay ${ }^{15}$ have reported an association between Fuchs' endothelial dystrophy and axial hypermetropia.

We are concerned to see that many of these patients were left with at least one hypermetropic meridian (i.e. a positive spherical error after conversion to negative cylinder), with the result that without optical correction at least one meridian would be blurred at all distances. Clearly a proportion were in fact hypermetropic in both optical meridia ( 16 of 51 eyes; $31 \%$ ) and therefore entirely dependent on optical correction for useful vision. In contrast, those patients who were left with a residual myopia were at least theoretically able to see something at short distances unaided.

The calculation of the IOL power presents a problem. For many patients it is possible to measure the curvature of the diseased cornea, and this is of use in calculating the optimal IOL power. ${ }^{7}$ Occasionally, it may not be possible to measure the corneal curvature of the eye to be operated on. In the absence of documented axial ametropia or a history of clinically significant anisometropia, it seems reasonable to obtain k-readings from the contralateral eye for the calculation of the IOL power, although these may have to be altered in the light of the likely post-grafting $\mathrm{k}$-values if such data are available. An alternative possibility might be to obtain k-values from soft contact lenses with a very high water content allowed to settle on the cornea to be grafted, although we are unaware of any data supporting this hypothesis. This series suggests that those patients whose IOL power was based on biometry (as opposed to the use of standardised or estimated IOL power) fared worst in terms of post-operative ametropia. This may possibly be because these were the most ame- tropic patients pre-operatively in whom it was hoped biometry would be most helpful, and highlights the problem of ametropia in these patients. The SRK formula is known to be inaccurate in extremes of ametropia.

\section{Refractive Results: Astigmatic Error}

Although there have been claims of superior refractive results from specific keratoplasty suture techniques, ${ }^{6,8,9,16}$ we were unable to find any objective evidence of less astigmatism in grafts sutured with interrupted sutures compared with those with a continuous suture. The proportion requiring graft refractive surgery is similar to that in a group of keratoconic patients recently reported. ${ }^{12}$

\section{Manpower}

A major resource demand in ophthalmology is the staffing of outpatient clinics. Few series have commented on the number of post-operative visits following corneal surgery. The patients reported here attended 11 times in their first post-operative year and 5 in the second. These figures are in good agreement with those of Ménage and Claoué, ${ }^{17}$ Claoué and Falcon ${ }^{18}$ and Claoue et al. ${ }^{13}$ although the series are not precisely comparable. In addition to seeing an ophthalmologist these patients are likely to need to be seen by an optometrist and/or a contact lens practitioner a number of times in the first 2 years after surgery and this will all need to be taken into account when calculating staffing levels. We believe that such a large number of visits may not be the minimum that is clinically essential, and this aspect is currently under review.

\section{Conclusion}

This series shows that a significant proportion of patients are hypermetropic after corneal triple procedures, with resulting poor unaided visual acuity. We believe that as most surgeons are unable accurately to predict post-operative k-readings for their patients, careful consideration is required before using reduced-power IOL implants for patients undergoing corneal triple procedures. In the absence of documented high axial myopia they may best be avoided.

We wish to thank Mr. N. S. C. Rice, Mr. P. Wright and Mr. J. K. G. Dart for allowing us to study patients under their care, and Miss K. E. Stevenson for helpful comments on the manuscript.

Key words: Cataract surgery, Epidemiology, Intraocular lens (IOL), Keratoplasty, Refractive error.

\section{REFERENCES}

1. Katzin HM, Meltzer JF. Combined surgery for corneal transplantation and cataract extraction. Am J Ophthalmol 1966; 62:556-60.

2. Taylor DM. Keratoplasty and intra-ocular lenses. Ophthalmic Surg 1976;7:31-42.

3. Weisenthal RW, Whitson WE, Krachmer JH. Corneal surgery. In: Tasman W, Jaeger EA, editors. Duane's clinical ophthalmology. Vol. 5. Philadelphia: Lippincott, 1989: $1-46$.

4. Ficker LA, Kirkness CM, Steele ADMcG, Rice NSC, Gilvarry AME. Intraocular surgery following penetrating keratoplasty: the risks and advantages. Eye 1990;4:693-7.

5. Katz HR, Forster RK. Intraocular lens calculation in com- 
bined penetrating keratoplasty, cataract extraction and intraocular lens implantation. Ophthalmology 1985;92:1203-7.

6 . Binder PS. Intraocular lens powers used in the triple procedure: effect on visual acuity and refractive error. Ophthalmology 1985;92:1561-6.

7. Crawford GJ, Stulting RD, Waring GO, van Meter WS, Wilson LA. The triple procedure: analysis of outcome, refraction, and intraocular lens power calculation. Ophthalmology 1986;93:817-24.

8. Binder PS. The triple procedure. Refractive results: 1985 update. Ophthalmology 1986;93:1482-8.

9. Mattax JB, McCulley JP. The effect of a standardized keratoplasty technique on IOL power calculation for the triple procedure. Acta Ophthalmol (Copenh) 1989;67(Suppl 192): 24-9.

10. Kirkness CM, Cheong PYY, Steele ADMcG. Penetrating keratoplasty and cataract surgery: the advantages of an extracapsular technique combined with posterior chamber intraocular implantation. Eye 1987;1:557-61.

11. Geggel HS. Intraocular lens implantation after penetrating keratoplasty: improved unaided visual acuity, astigmatism and safety in patients with combined corneal disease and cataract. Ophthalmology 1990;97:1460-7.
12. Kirkness CM, Ficker LA, Steele ADMcG, Rice NSC. The success of penetrating keratoplasty for keratoconus. Eye 1990;4:673-88.

13. Claoué CMP, Falcon MG, Shilling JS. Penetrating keratoplasty in south east London 1981-1986: epidemiological aspects and demands on medical resources. J R Soc Med 1990;83:245-8.

14. Coster DJ. Some factors which affect the visual outcome of corneal transplantation. Eye 1991;5:265-78.

15. Pitts JF, Jay JL. The association of Fuchs' corneal endothelial dystrophy with axial hypermetropia, shallow anterior chamber and angle closure glaucoma. $\mathrm{Br} \mathrm{J}$. Ophthalmol 1990;74:601-4.

16. Musch DC, Meyer RF, Sugar A, Soong HK. Corneal astigmatism after penetrating keratoplasty: the role of suture technique. Ophthalmology 1989;5:698-703.

17. Ménage MJ, Claoué CMP. Severe herpetic keratitis. II. The cost of penetrating keratoplasty. J R Soc Med 1988;81: 526-7.

18. Claoué CMP, Falcon MG. Medical manpower requirements following penetrating keratoplasty for herpes simplex keratitis. Acta Ophthalmol (Copenh) 1991;69:105-7. 